\title{
HYBRID PI FUZZY LOGIC CONTROLLER FOR BOOST CONVERTER OPERATING IN PV ENERGY SYSTEM
}

\author{
H.A.Mohamed H.A.Khattab* A.Mobarka * G.A.Morsy* \\ *Electrical Department, Faculty of Engineering, Menoufia, University, \\ Shebin El-Kom, Egypt.
}

\begin{abstract}
The demand for high efficiency DC/DC boost converters is increasing dramatically in many areas of industrial applications especially for PV system to produce high voltage to meet the needs of the load. Closed-loop systems are designed to automatically attain and keep the desired output condition by comparing it with the actual condition. In this paper, Hybrid Proportional-Integral Fuzzy Logic Controller (HPIFLC) is designed and implemented to control the duty cycle of DC/DC boost converter. This combination of Proportional-Integral (PI) and Fuzzy Logic (FL) is done to exploit the advantageous sides of both controllers to obtain better performance. The system under consideration consists of a PV module connected to the load through a controlled DC/DC boost converter. The mathematical model of the complete power system and the simulation has been done using MATLAB/SIMULINK. Performance comparison between PI, FL, and HPIFLC controllers have been carried out which emphasize that HPIFLC is superior to the other controllers as rise time, settling time, overshoot and steady state error are reduced.

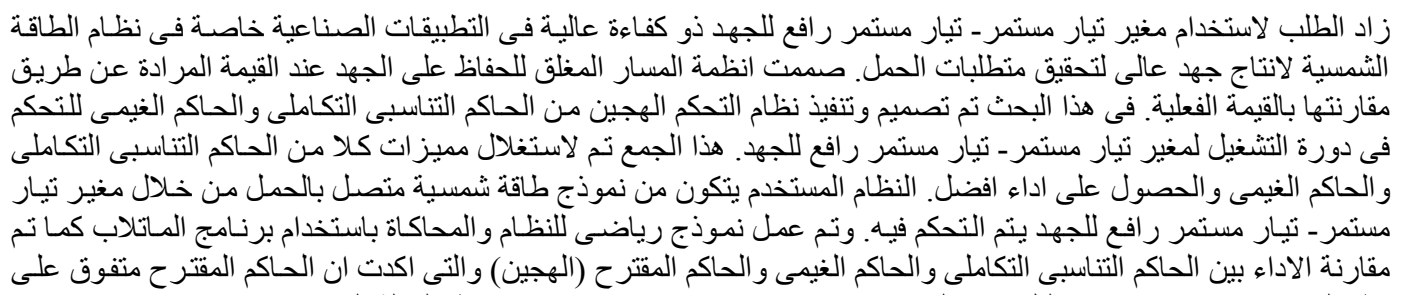

Keywords: PV, Boost converter, PI, FLC, HPIFLC.

\section{Introduction}

The prices of non-renewable energy sources such as coal, natural gases and oil are skyrocketing and the use of such sources causes serious consequences such as air pollution, water pollution and greenhouse effect etc, which led to global warming so much effort has been pushed towards renewable sources of energy as alternative sources [1]. Photovoltaic (PV) system is undoubtedly the most impressive renewable energy sources which has the advantages of being environmentally friendly, pollution free, relative lack of noise or movement, easy to install and has unlimited availability. So, PV energy system is likely recognized and widely utilized to the forefront in electric power applications. The main applications are in either standalone generating unit or grid connected [2]. The output power of PV system is very less compared with load requirements so boost converter is needed for high voltage. These converters have received a great deal of interest in a lot of applications including power supplies for personal computers, laptop computers, smart phones, dc motor drives and especially for PV system. This is due to their advantageous features in terms of size, efficiency and reliable operation. In PV system, DCDC converters are connected between the source and the load which converts unregulated dc input voltage to regulated output dc voltage [3]. Considerable attention has been directed to the control of DC/DC boost converter to improve the performance of the closed loop system.

PI controller is one of the earliest control techniques that is still used widely for several decades in industrial application because of its easy implementation, robust performance including low percentage overshoot and small settling time for slow process plants and being simple of physical principle of its parameters [4]. It has been realized that classical PI controllers are effective for linear systems but not suitable for nonlinear and complex 
systems. Latterly, fuzzy set theory is a good suggestion targeting industrial applications and added a promising new dimension to the existing domain of conventional control systems as it represents an excellent concept to close the gap between human reasoning and computational logic [5]. So, scientists and researchers use fuzzy logic due to its ability to translate the operator's experience and heuristics into the rule base. Also, Fuzzy logic control (FLC) is an ideal solution for applications where a mathematical model is known or not precisely known especially for problems with varied parameters and nonlinear models [6]. This is more suitable especially for PV where modeling an accurate photovoltaic has been a great challenge for scientists for several years. The major disadvantage of FLC is the presence of steady state error. To eliminate this disadvantage, it is necessary to combine Fuzzy Logic control with another suitable control technique, which is capable of removing the disadvantage existing in Fuzzy Logic control [7].

So, the main objective of this paper is to design Hybrid PI Fuzzy controller (HPIFLC) to take advantages of both PI and FLC controllers to obtain better performance for the PV energy system including PV module, DC/DC boost converter with its duty cycle controller and load. The performance of the proposed controller is compared with those obtained when either the classical PI or the fuzzy controller to validate the effectiveness of HPIFLC.

\section{Studied System}

The system under consideration is shown in Fig. 1 which consists of a PV module connected to the load through a controlled DC/DC boost converter. The equivalent circuit of $\mathrm{PV}$ and its electrical characteristics data are listed in Appendix A. The DC-DC boost converters are used to convert the unregulated DC input voltage, supplied by PV modules, to a controlled DC output at a higher voltage level required by the loads. The mathematical model and design procedure of DC/DC boost converter are presented in [8].The output voltage of boost converter is given by

$$
V_{o}=\frac{V_{s}}{1-D}
$$

where $D$ is the duty cycle, $D=t_{o n} / T$ and $T=1 / F_{s}$. $V_{o}$ : The average output voltage, $\mathrm{V}$.

$V_{s}$ : The input voltage, $\mathrm{V}$.

$t_{o n}$ : The switching on time of the electronic switch, s.

$T$ : The switching period, s.

$F_{s}$ : The switching frequency, Hz.
The designed parameter and the components values of the studied DC/DC boost converter are $\mathrm{L}=750$ $\mathrm{mH}, \mathrm{C}=100 \mu \mathrm{F}$ and the switching frequency is considered $\mathrm{F}_{\mathrm{s}}=5 \mathrm{kHz}$ when $\mathrm{V}_{\mathrm{s}}=12 \mathrm{~V}$ from $\mathrm{PV}$ module.

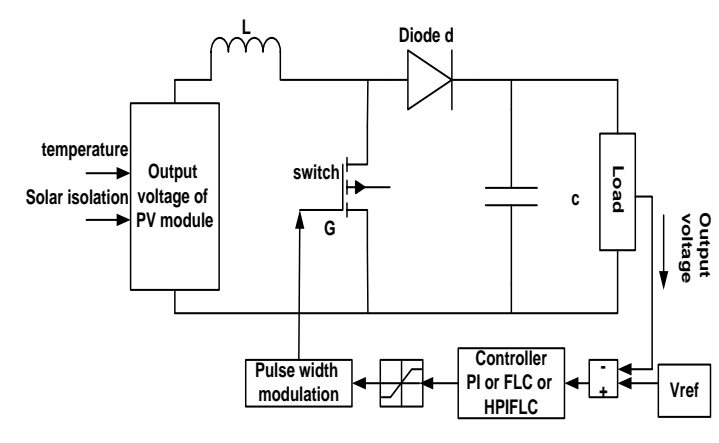

Fig. 1. The block diagram of proposed system.

\section{Closed loop controller techniques}

Design and implementation of a control system require the use of efficient techniques that provide simple and practical solutions in order to fulfill the performance requirements. The closed loop control of DC/DC boost converter goes through the following three controllers.

\subsection{PI CONTROLLER}

PI controller is a generic feedback loop controlling mechanism which corrects the error between a measured value and a desired set point by calculating it firstly, and then a corrective action adjust the process according to the requirement. The PI controller calculation involves two separate parameters. The proportional gain $\left(\mathrm{K}_{\mathrm{P}}\right)$ is also called adjustable amplifier which in most systems is responsible for process stability, and the integral gain $\left(\mathrm{K}_{\mathrm{I}}\right)$ is responsible for driving error to zero [9],[10]. Fig. 2 illustrates PI controller boost converter block diagram to regulate its output voltage $V_{o}$ and current $I_{o}$.

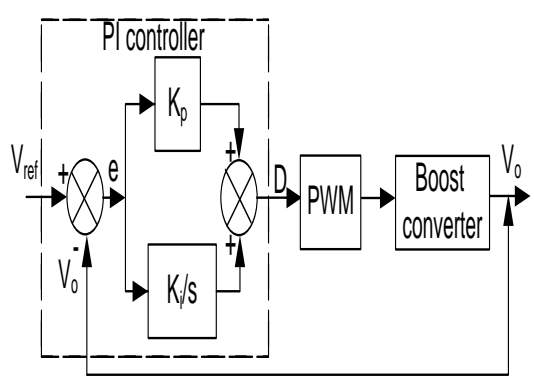

Fig. 2. Basic structure of PI controller. 


\subsection{Fuzzy Logic}

Fuzzy logic control is one of the artificial intelligence control techniques which have been successfully applied as good alternative for various control fields. Fig. 3 shows the basic configuration of FLC, which comprises four principle components: a fuzzification, rule base, inference engine and defuzzification [11].

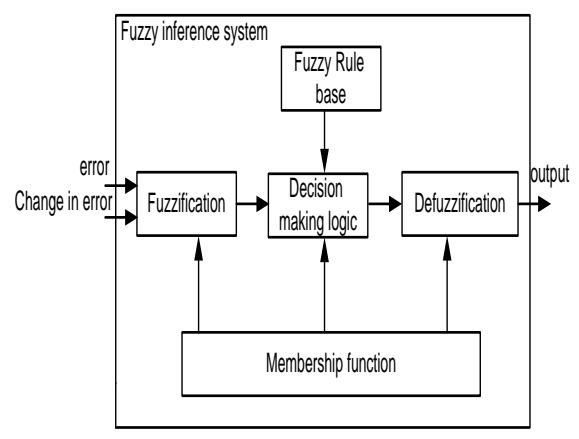

Fig. 3. Block diagram of fuzzy logic controller.

Firstly, the crisp input is converted into fuzzy set by using fuzzification method. After fuzzification, the rule base is formed which is the heart of the fuzzy controller and the most usual source for constructing linguistic control rules is human experts. The rules are in "If Then" form where the "If" side is called the conditions and the "Then" side is called the conclusion. The computer is able to implement the rules and calculate a control signal depending on the measured inputs error (e) and change in error (de) [12]. Table I shows the used rule base for FLC. Five triangular membership functions are used for fuzzification of the two inputs (error and change in error) and defuzzification for the output as shown in Fig. 4. Defuzzification process takes place when all the actions that have been done are combined and converted into a single precise output signal which is the control signal of the system by the center of gravity or the weighted average. Defuzzification interface is the inverse of the fuzzification interface, the fuzzy conclusion is defuzzified, i.e., converted into numerical output.[13-14]

Table I. Fuzzy Rules for Boost Converter

\begin{tabular}{|l|l|l|l|l|l|}
\hline dele & NB & NS & ZO & PS & PB \\
\hline NB & NB & NB & NB & NS & ZO \\
\hline NS & NB & NB & NS & ZO & PS \\
\hline ZO & NB & NS & ZO & PS & PB \\
\hline PS & NS & ZO & PS & PB & PB \\
\hline PB & ZO & PS & PB & PB & PB \\
\hline
\end{tabular}

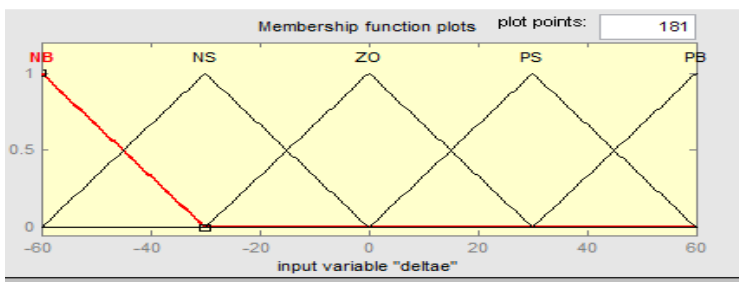

(a)

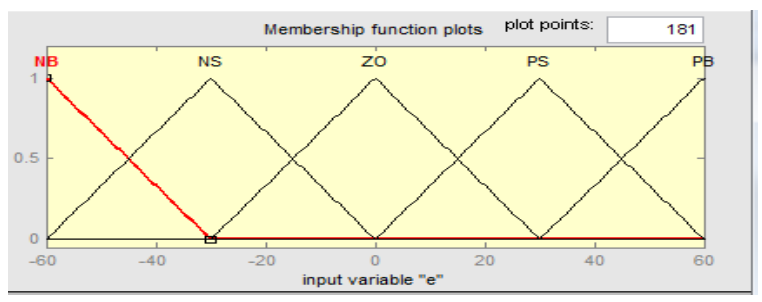

(b)

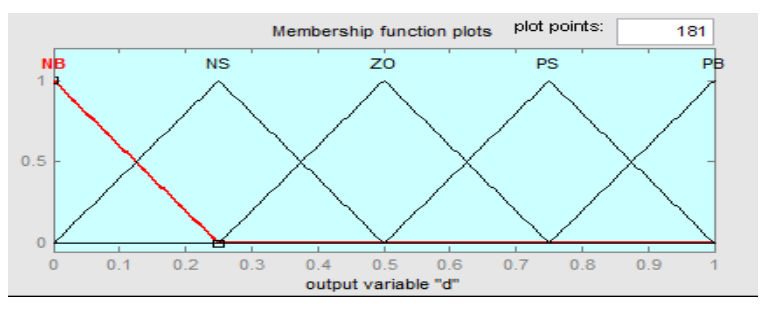

(c)

Fig. 4. The membership functions of (a) error, (b) change of error, (c) duty ratio.

\subsection{Hybrid Fuzzy-PI Controller}

Hybridization means combination of two different categories. It is a process to combine the performance of two different controllers to achieve better performance than individual controllers. Therefore a hybrid controller is designed using the two controllers to improve the performance of DCDC Boost converter. PI controllers are able to control and minimize the steady state error of the system but have less effect role in the dynamic response. Fuzzy controllers do not need precise information about the system variables in order to be effective. So, a hybrid controller is proposed to utilize the advantages of both PI controller and fuzzy controller to produce better performance than either PI or FLC $[6,15,16]$. In this section, a hybrid controller is designed using PI which is connected in series with FLC as shown in Fig. 5. 
Rederence

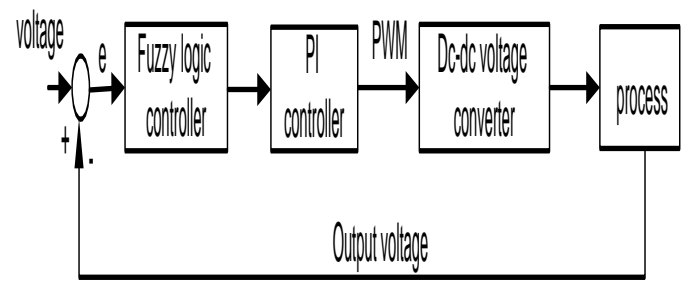

Fig. 5. Block diagram of a HPIFLC.

\section{Simulation results}

The complete power system is modeled and simulated using MATLAB/SIMULINK to investigate the effectiveness of the proposed controller as shown in Fig. 6. Fig. 7 shows the simulation results in a comparative form with open loop, PI, FLC and HPIFLC in the closed loop control of DC/DC boost converter for different set points of $40,60,120 \mathrm{~V}$

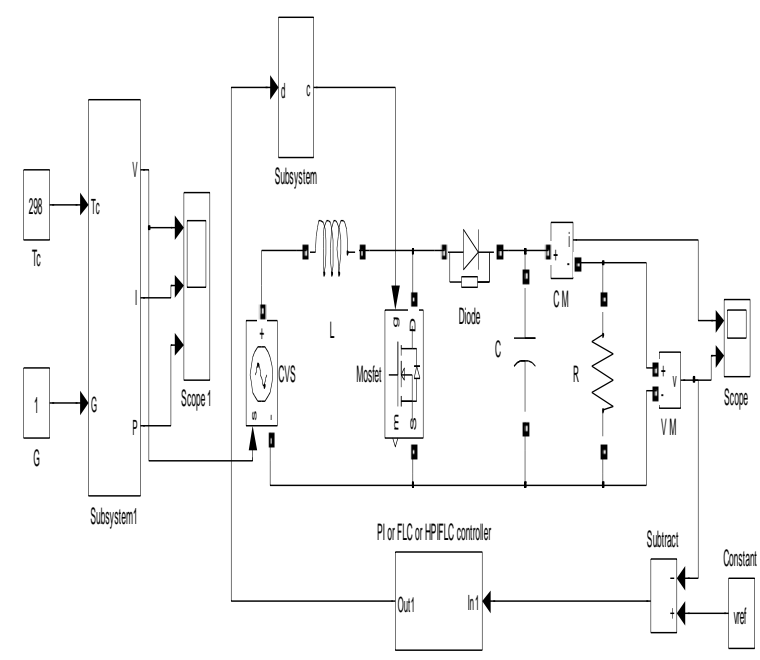

Fig. 6. MATLAB SIMULINK of closed loop hybrid controller.

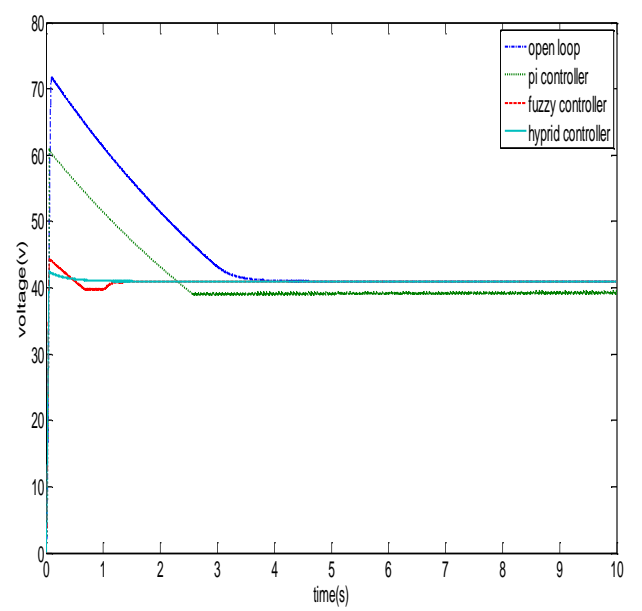

(a)

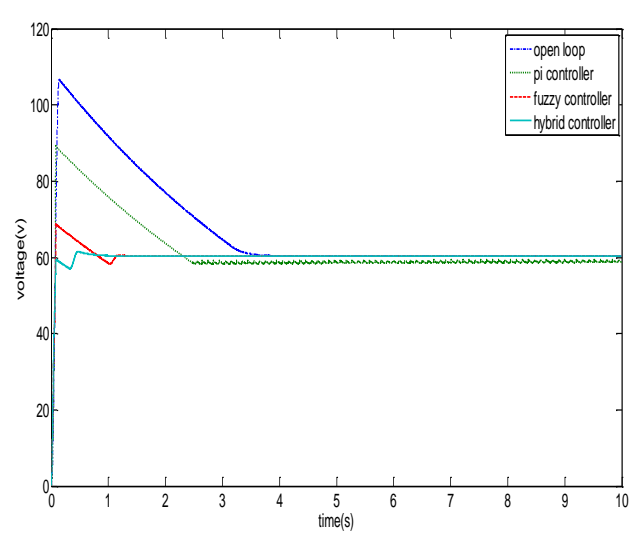

(b)

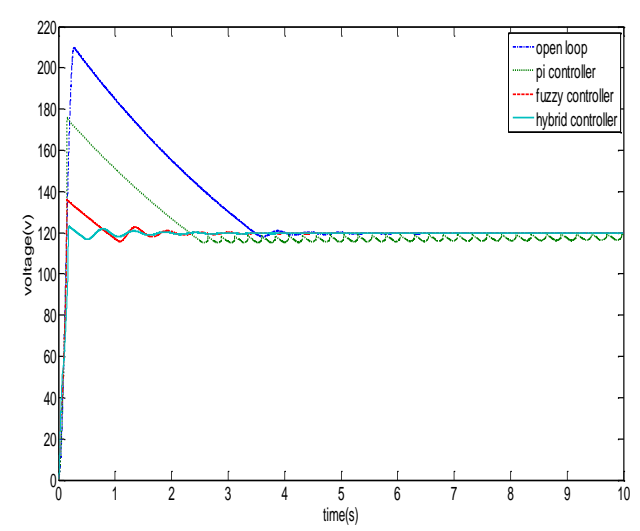

(c)

Fig. 7. Output voltage for different reference voltage (a) Vref=40,(b) Vref=60, (c) Vref=120.

It can be observed that the open loop of studied power system needs control to improve the performance. This is performed by using PI or FLC or HPIFLC as closed loop controllers for DC/DC boost converters. Since PI controller has maximum overshoot but minimum value is obtained by FLC. Also, during steady state conditions, the settling time of FLC was found to be more when compared to PI controller. In this HPIFLC, this is compensated by combined action of PI and FLC. So, HPIFLC achieves the main target which is obtaining the desired output voltage with high accuracy despite of changing of duty cycle of DC-DC boost converter.

\section{Conclusions}

This paper presents the design and implementation of hybrid PI fuzzy controller for the duty cycle of DC/DC boost converter. The objective of the hybrid controller is to utilize the best attributes of the PI and fuzzy logic controllers. The proposed system used solar PV as the input, DC/DC boost converter with 
its duty cycle controller and the load. The closed loop control is necessary to maintain the output voltage constant. The performance of the closed loop is investigated using MATLAB/SIMULINK. From the comparative simulation results, it is concluded that the response with PI exhibits some overshoot and that with FLC reduces the overshoot but with steady state error. HFLPI gets quick response and eliminates the overshoot for different duty cycles of the DC/DC boost converter. Also, the proposed controller forces the output voltage to tightly track the reference voltage despite the changing of the duty cycle. So, the system performance with HPIFLC in both transient and steady state is improved when compared to either classical PI or FL controllers in terms of reducing rise time, overshoot and peak time.

\section{References}

[1] R. Singh, M. Pandit, "analysis of photovoltaic cells with closed loop boost converter," International Journal of Advances in Engineering \& Technology, Mar 2013.

[2] R. Arulmurugan, N.S.Vanitha, "optimal design of dc-dc boost converter with closed loop control PID mechanism for high voltage photovoltaic application," International Journal of Power Electronics and Drive System (IJPEDS), Vol. 2, No. 4, December 2012.

[3] Smitha K ,Priyanka G Aryar ,Renuka Bijlwan,Sachin Angadi,"steady state analysis of pid controlled boost converter using state space averaging technique,"Multidisciplinary Journal of Research in Engineering and Technology, Pg.100-110, issn:2348-6953.

[4] Anil Gunde, Devadasu Ghanta,"intelligent hybrid fuzzy PID control of an inverted pendulum," CMR Journal of Engineering and Technology, Vol.1 Issue.1 January - June, 2016.

[5] Rahul Malhotra, Narinder Singh, Yaduvir Singh,"Fuzzy Logic Modelling, Simulation and Control: A Review," International Journal of Computer Sci ence and Technology, Vol. 1, Iss ue 2, December 2010.

[6] Abd El-Shafy A. Nafeh," Fuzzy Logic Operation Control for PV-Diesel-Battery Hybrid Energy System," The Open Renewable Energy Journal, Volume 2,2009.

[7] Reshmi R, Sumi Babu," Design \& Control of DC-DC Converter using Hybrid Fuzzy PI Controller," IJREAT International Journal of Research in Engineering \& Advanced Technology, Volume 1, Issue 3, June-July, 2013.
[8] H.A.Mohamed, H.A.Khattab, A.Mobarka, G.A.Morsy," Design, Control and Performance Analysis of DC-DC Boost Converter for StandAlone PV System," 2016 Eighteenth International Middle-East Power Systems Conference (MEPCON), December 27-29, 2016 - Helwan University, Cairo - Egypt.

[9] A.A. Bakar, W. M. Utomo, T. Taufik, S. Aizam, Jumadril," dc/dc boost converter with pi controller using real-time interface," ARPN Journal of Engineering and Applied Sciences, issn:1819-6608, Vol. 10, No. 19, October 2015.

[10] Mitulkumar R. Dave, K.C.Dave," analysis of boost converter using pi control algorithms," International Journal of Engineering Trends and Technology, Volume3, Issue2, 2012.

[11]R. K. Ahuja, R. Kumar, "Design and Simulation of Fuzzy Logic Controller based Switched-Mode Power Supply," International Journal of Electrical Engineering, Vol. 2, Issue-5, May 2014.

[12] R. B. Caldo, "Fuzzy Logic Simulation of DCDC Boost Converter Using Matlab Fuzzy Logic Toolbox," NNGT Journal: International Journal of Information Systems, Vol. 1, July 30-2014.

[13] Chetan P. Ugale, R. B. Dhumale, V. V. Dixit," dc-dc converter using fuzzy logic controller," International Research Journal of Engineering and Technology (IRJET),ISSN: 2395 -0056, Volume: 02 Issue: 04, July-2015.

[14] T. Deepa, "Performance comparison of boost converter by using fuzzy logic controller," global journal of advanced research, Vol. 2, Issue-3, PP. 629-637, March 2015.

[15] R.Anand, P.Melba Mary," comparison of pid and fuzzy controlled dc to dc converter with inductor resistance," International Journal of Science and Research technology, ISSN: 2277-9655, August 2013.

[16]Danish Chaudhary, Prof. Aziz Ahmed, Anubha Mangal," Comparative Analysis of the PI, Fuzzy and Hybrid PI-Fuzzy Controllers Based DVR," International Journal of Emerging Technology and Advanced Engineering,Volume 5, Special Issue 1, April 2015. 


\section{Appendix[A]}

The equivalent circuit of a PV cell is shown in Fig. A1 [1,2] and its electrical characteristics data at STC is shown in Table A1 [8].

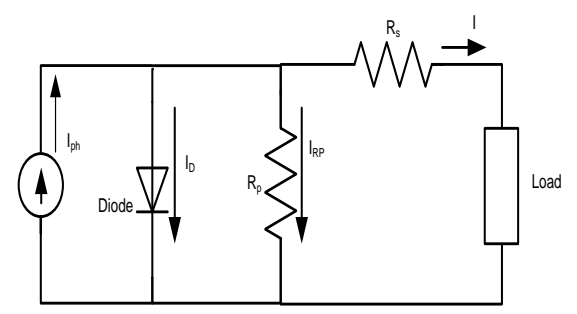

Fig. A1. Equivalent circuit of a PV cell.

Table A1. Electrical charecteristics data of PV module at STC

\begin{tabular}{|l|l|}
\hline Description & Rating \\
\hline Rated power & $35.14 \mathrm{~W}$ \\
\hline Voltage at maximum power $\left(V_{m p}\right)$ & $12.075 \mathrm{~V}$ \\
\hline Current at maximum power $\left(I_{m p}\right)$ & $2.91 \mathrm{~A}$ \\
\hline Open circuit voltage $\left(V_{O C}\right)$ & $14.75 \mathrm{~V}$ \\
\hline Short circuit current $\left(I_{S C}\right)$ & $3.21 \mathrm{~A}$ \\
\hline Total number of cells in series $\left(N_{s}\right)$ & 25 \\
\hline $\begin{array}{l}\text { Total number of cells in } \\
\text { parallel }\left(N_{p}\right)\end{array}$ & 1 \\
\hline
\end{tabular}


H.A.Mohamed, H.A.Khattab, A.Mobarka, G.A.Morsy “HYBRID PI FUZZY LOGI..." 